\title{
Multi-objective Optimized Capacity Configuration Model of Isolated Microgrid Considering Life of Stored Energy
}

\author{
Min Zhang, Lin Zhang, Bin Wang, Yi Feng, Laihong Xiong, Wenzhong Cao \\ State Grid Chongqing Electric Power Company \\ Chongqing, China
}

\begin{abstract}
The optimal capacity combination model of an isolated microgrid is established, which considers the pollution emissions, the punishment of renewable energy waste, the effect of charge and discharge process of lead-acid battery to its lifetime and reliability, the total cost and punishment of renewable energy waste are considered as the two objective functions. This paper establishes isolated microgrid multi-target capacity optimization configuration model, and the adaptive genetic algorithm is proposed to solve the problem,then the paper analyses the effect of the punishment of wind energy waste and the reliability to capacity combination of microgrid. Example analysis results show that the punishment of wind energy waste has great effect to capacity combination of microgrid. The punishment of wind energy waste should be considered in the network planning; the reliability also has a great influence on the microgrid planning, and the different investment schemes should be selected according the different user reliability requirements.
\end{abstract}

Keywords-microgrid; power capacity configuration optimization; penalty fee for wind curtailment

\section{INTRODUCTION}

Microgrid, an integration of various distributed generators, energy storage equipment and load and control devices, can perform conversion operation between parallel mode and island mode to realized efficient utilization of new energy ${ }^{[1-2]}$. However, input cost of distributed generators is high. Rational capacity configuration of micro sources based on load condition and regional wind energy resource characteristic is of significant research importance $^{[3]}$

There have been many studies on capacity configuration optimization of isolated microgrid. Most of the papers [4-9] study the capacity configuration optimization of isolated microgrid from the perspective of economical efficiency and environmental protection, yet few of them have considered about the effect of system reliability and excessive electric energy. Also, the service life of storage equipment hasn't been taken into account.

On the basis of existing researches, this paper builds mathematic model of various micro sources for the microgrid and especially analyzes the effect of charge and discharge on the life of storage equipment. To reduce consumption of conventional energy, this paper develops relevant microgrid operation strategies. Besides, directing at the minimum total cost and penalty fee for wind curtailment, it builds a multi-objective optimized capacity configuration model of microgrid considering life of stored energy. Genetic algorithm is adapted to solve the problem. At the end, the effectiveness of this model is verified with analysis of examples.

\section{MATHEMATIC MODEL OF MICRO SOURCE}

\section{A. Model of micro-gas turbine}

Micro-gas turbine (micro turbine for short) usually refers to small gas turbine fueled by natural gas and methane ${ }^{[10]}$.

The relation between fuel consumption cost and generated output during the micro turbine operation is as shown in the formula below:

$$
F_{F C}=F_{f} \sum_{t} \frac{P_{t}}{\eta_{t}}
$$

In this formula, ${ }_{F C}$ is the generating cost of micro turbine; $F_{f}$ is the fuel price; $P_{t}$ is the output power in period $t$ (defaulting to 1 hour in this paper); $\eta_{t}$ is the efficiency of turbine in period $t$.

\section{B. Model of wind turbine generator}

The relation between the output power and wind speed is expresses with piecewise function in Reference [11].

\section{Model of stored energy}

Storage equipment are a necessary part in the microgrid to balance fluctuation of intermittent energy sources. Lead-acid battery is the most developed energy storage technique and has been most widely applied to microgrid. A lead-acid battery being cha[rged during the operation follows the formula below:

$$
S_{o c}(t+1)=S_{o c}(t)+P_{t}^{c} \eta_{c} \Delta t
$$

In the state of discharging, it follows:

$$
S_{o c}(t+1)=S_{o c}(t)-P_{t}^{d} \Delta t / \eta_{d}
$$


In the formula, $S_{o c}(t+1)$ and $S_{o c}(t)$ are the residual capacity of lead-acid battery at time $t+1$ and $t$ respectively; $P_{t}^{c}$ and $P_{t}^{d}$ are the charge and discharge power of lead-acid battery at time $t$ respectively; $; \eta_{c}$ and $\eta_{d}$ are the charge and discharge efficiency of lead-acid respectively; $\Delta t$ is the time interval between the two times (defaulting to 1 hour in this paper).

\section{MULTI-OBJECTIVE CAPACITY}

\section{CONFIGURATION OPTIMIZATION OF ISOLATED}

\section{MICROGRID}

\section{A. Effect of storage equipment life on capacity configu-} ration optimization of microgrid

This paper lays particular emphasis on the effect of depth of charge and discharge and number of discharge cycles on life of lead-acid battery.

If the depth of charge and discharge of lead-acid battery is $R$, before any failure, the maximum number of discharge cycles can be expresses approximately as:

$$
N_{E S S}=\alpha_{1}+\alpha_{2} e^{\alpha_{3} R}+\alpha_{4} e^{\alpha_{5} R}
$$

In the formula, $\alpha_{1} \sim \alpha_{5}$ are the characteristic parameters provided by the manufacture.

Lead-acid battery loses $1 / N_{E S S}$ of its service life for each discharge cycle. After one year of service, the life loss of lead-acid battery is:

$$
C_{1}=\sum_{j=1}^{N_{T}} \frac{1}{N_{E S S, j}}
$$

And the life of the lead-acid battery is:

$$
C_{\text {life }}=1 / C_{1}
$$

In the formula, $j$ means that the lead-acid battery is in the $\mathrm{jth}$ discharge cycle; $N_{T}$ is the number of discharge cycles during the run cycle (the run cycle is 1 year in the planning process); $1 / N_{E S S, j}$ is the proportion accounted by the life loss of the lead-acid battery in the $j t h$ discharge cycle of the entire life; $C_{\text {life }}$ is the life of the lead-acid battery.

Life of lead-acid battery is closely related to depth of charge and discharge and number of discharge cycles. Equipment replacement is directly connected to equipment life As a result, the effect of lead-acid battery life on the capacity configuration optimization of isolated microgrid must be taken into consideration.

\section{B. Operation strategy of isolated microgrid}

This paper develops the operation strategy of microgrid to reduce the consumption of conventional energy.

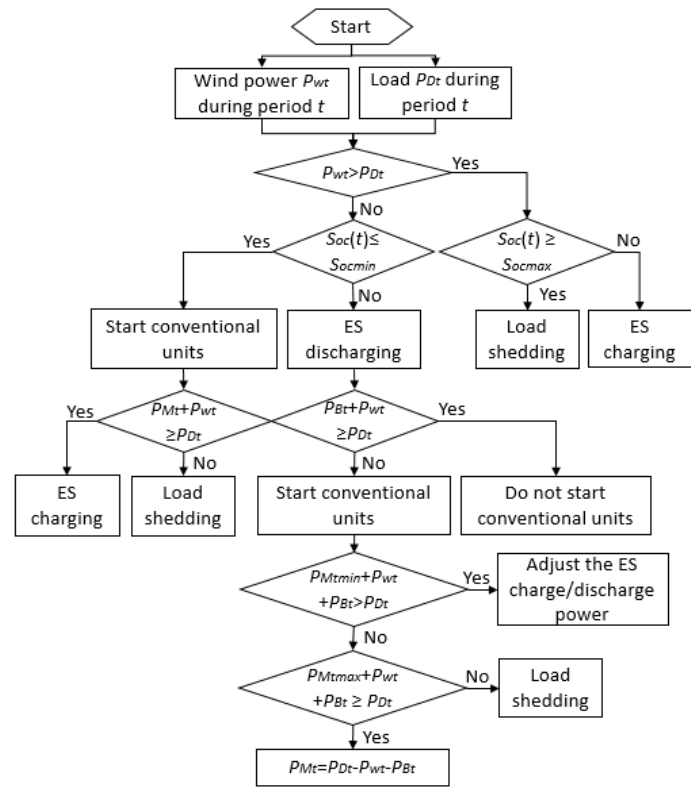

Figure 1. Flow chart of isolated microgrid operation strategy

Fig .1 shows the detailed flow of isolated microgrid operation strategy. This the chart,,$_{w t}$ is the wind power at time $t ; P_{D t}$ is the load at time $t ; P_{B t}$ is the discharge power of storage equipment at time $t$ (the value is negative in charging and positive in discharging); $S_{o c}(t)$ is the residual capacity of storage equipment at time $t ; S_{\text {ocmax }}$ and $S_{\text {ocmin }}$ are the maximum and minimum residual power of the storage equipment; $P_{M T}$ is the output of micro turbine; $P_{M \text { MTax }}$ and $P_{M \text { Tmin }}$ are the upper and lower limit of the output of micro turbine.

C. Optimized capacity configuration model of isolated microgrid

\section{1) Objective function}

This paper respectively takes the minimum cost of input and operation and minimum penalty fee for wind curtailment as objective functions and builds the optimized capacity configuration model of wind/storage/micro turbine combined system. The expression of the objective function is as below:

$$
\left\{\begin{array}{l}
\min F_{1}=C_{W T}+C_{M T}+C_{B}+C_{R}+C_{M}+C_{F}+C_{E} \\
\min F_{2}=E_{\text {windcut }} \cdot C_{\text {Windcut }}
\end{array}\right.
$$

In the formula, $F_{1}$ is the total cost of input and operation; $F_{2}$ is penalty fee for wind curtailment; $C_{W T}$ is the input cost of wind turbine generator; $C_{M T}$ is the input cost of micro turbine; $C_{B}$ is the input cost of lead-acid battery; $C_{M}$ is the operating maintenance cost of micro turbine; $C_{F}$ is the fuel consumption cost of micro turbine; $C_{E}$ is the environmental conversion fee; $C_{R}$ is the equipment replacement cost. When equipment life is shorter than engineering working year, equipment should be replaced. Assumes a single replacement of each kind of equipment costs the same with its input; $E_{\text {windcut }}$ is the rate of curtailed air; $C_{\text {Windcut }}$ is the unit penalty fee for wind curtailment.

a) Equipment input cost in uniform annual value

In uniform annual value, the input cost of various 
types of equipment is:

$$
\begin{aligned}
C_{W T} & =N_{W T} e_{W T} P_{W T} \frac{r(1+r)^{Y_{W T}}}{(1+r)^{Y_{W T}}-1} \\
C_{M T} & =N_{M T} e_{M T} P_{M T} \frac{r(1+r)^{Y_{M T}}}{(1+r)^{Y_{M T}}-1} \\
C_{B} & =N_{B} e_{B} P_{B} \frac{r(1+r)^{Y_{B}}}{(1+r)^{Y_{B}}-1}
\end{aligned}
$$

In the formula, $N_{W T}, N_{M}$ and $N_{B}$ are the number of wind turbine generators, micro turbines and batteries respectively; $e_{W T}, e_{M T}$ and $e_{B}$ are the unit equipment input cost of wind turbine generator, micro turbine and battery respectively; $P_{W T}, P_{M T}$ and $P_{B}$ are the installed capacity of a single wind turbine generator, micro turbine and battery respectively; $Y_{W T}, Y_{M T}$ and $Y_{B}$ are the life of wind turbine generator, micro turbine and battery respectively. Service life of battery is related to its operation process. Section III shows the computational process in detail; $r$ is the discount rate.

\section{b) Operating maintenance cost}

DG operating maintenance cost can be computed via Formula (12).

$$
C_{M}=\sum_{i=1}^{N} P_{i} K_{\mathrm{OM}_{i}}
$$

In the formula, $N$ is the type number of power sources; $P_{i}$ is the installed capacity of the ith power source; $K_{\mathrm{Om}}$, in $\$ /(\mathrm{kW} \cdot \mathrm{a})$, is the proportionality coefficient of the operating maintenance cost of the ith power source.

c) Fuel consumption cost

See the computation of micro turbine's fuel cost in Section II.

\section{d) Environmental conversion fee}

Based on Reference [12], this paper converts the effect of pollutant discharge on environment into cost:

$$
C_{E}=W \sum_{k=1}^{M} v_{k}\left(V_{k 1}+V_{k 2}\right)
$$

In the formula, $W$ is the annual energy output of micro turbines; $M$ is the type of pollutant; $v_{k 1}$ and $v_{k 2}$ are the environmental value of the $k t h$ pollutant and the penalty for using it respectively.

Table I. EMISSION CHARACTERISTICS OF MICRO SOURCE $\mathrm{G} /(\mathrm{kWh})$

\begin{tabular}{ccccc}
\hline Unit & $\mathbf{N O}_{\mathbf{x}}$ & $\mathbf{C O}_{\mathbf{2}}$ & $\mathbf{C O}$ & $\mathbf{S O}_{\mathbf{2}}$ \\
\hline Micro Turbine & 0.619 & 184 & 0.170 & 0.000928 \\
\hline
\end{tabular}

Table II .FIG. ENVIRONMENTAL VALUE STANDARD OF POLLUTANT EMISSION IN POWER INDUSTRY

\begin{tabular}{ccccc}
\hline Coefficient & $\mathbf{N O}_{\mathbf{x}}$ & $\mathbf{C O}_{\mathbf{2}}$ & $\mathbf{C O}$ & $\mathbf{S O}_{\mathbf{2}}$ \\
\hline $\begin{array}{c}\text { Environmental value } \\
(\$ / \mathrm{kg})\end{array}$ & 1.000 & 0.002875 & 0.125 & 0.750 \\
Penalty $(\$ / \mathrm{kg})$ & 0.250 & 0.001250 & 0.020 & 0.125 \\
\hline
\end{tabular}

The discharge coefficient of micro turbine and the environmental value standard in power industry are as shown in Table 1 and 2.

2) Constraint condition

a) Number constraint of micro sources

The maximum installed number of various micro sources is constrained by the floor area:

$$
\begin{gathered}
N_{W T, \max }=\left[\frac{L}{8 d}+1\right] \cdot\left[\frac{W}{4 d}+1\right] \\
N_{B, \max } \leq\left[\frac{S}{S_{B}}\right]
\end{gathered}
$$

In the formula, $N_{M T \text {, max }}$ is the maximum number of micro turbines; $N_{B \text {, min }}$ and $N_{B \text {, max }}$ are the minimum and maximum numbers of installed batteries respectively; $S, L$ and $W$ are the given floor area, length and width respectively; $S_{B}$ is the floor area of a single battery.

b) Constraint on the output of micro turbine

c) Constraint on charge and discharge of lead-acid battery

Constraint on the rated power of lead-acid battery:

$$
\begin{gathered}
0 \leq P_{t}^{c} \leq P_{c h, \text { max }} \\
0 \leq P_{t}^{d} \leq P_{d c h, \text { max }}
\end{gathered}
$$

In the formula, $P_{t}^{c}$ and $P_{t}^{d}$ are the charge and discharge power of lead-acid battery respectively at time $t ; P_{c h, \max }$ and $P_{d c h, \max }$ are the maximum charge and discharge power respectively.

$$
S_{\text {ocmin }} \leq S_{o c}(t) \leq S_{\text {ocmax }}
$$

In the formula, $S_{o c}(t)$ is the residual capacity of lead-acid battery at time $t ; S_{\text {ocmin }}$ and $S_{\text {ocmax }}$ are the minimum and maximum residual capacity of lead-acid battery.

d) Reliability constraint

$$
L O L P \leq L O L P_{\max }
$$

In the formula, $L O L P_{\max }$ is the maximum loss of load probability allowed by the system.

Based on the operation strategy of microgrid as mentioned in Section III, this paper computes the annual reliability index of the microgrid. In case the maximum output of all power sources cannot meet the load requirement at time $t$, the quantity of load loss $E_{c u t, t}$ is:

$$
\begin{gathered}
E_{c u t, t}=\left(P_{\text {load }, t}-P_{B t}-P_{w t}-P_{M T}\right) \cdot \Delta t \\
L O L P=\sum_{t=1}^{T_{1}} E_{\text {cut }, t} / \sum_{t=1}^{8760}\left(P_{\text {load }, t} \cdot \Delta t\right)
\end{gathered}
$$

In the formula, $T_{1}$ is the time when power shortage occurs, 
and $\Delta t$ is the time interval ( 1 hour as defined by this paper).

\section{SOLUTION METHOD FOR MODEL}

Using Genetic Algorithm (GA) to solve the proposed model.

\section{A. Chromosome coding}

The chromosome can be expressed as $X=\left(x_{1}, x_{2}, x_{3}\right) . x_{1}$, $x_{2}$ and $x_{3}$, the array of binary code, represent the installed number of wind turbine generators, micro turbines and batteries respectively.

\section{B. Fitness function}

The expression of fitness function of this paper is as shown in Formula (24).

$$
\text { fitness }(x)=\frac{1}{F(x)+\operatorname{pen}(x)+A}
$$

$$
\operatorname{pen}(x)=\left\{\begin{array}{cc}
\delta \cdot\left(L O L P-L O L P_{\max }\right) & L O L P>L O L P_{\max } \\
0 & L O L P \leq L O L P_{\max }
\end{array}\right.
$$

In the formula, $F(x)$ is the linear weighted sum of the values of the two corresponding functions of chromosome $x ; A$ is the positive constant; $\operatorname{pen}(x)$ is the penalty term; $\delta$ is the positive constant.

\section{Algorithm flow}

Computation focusing on the weight coefficient scheme of one of the two objective functions follows the following steps:

Step1: Input necessary data for wind speed and load computation and set relevant parameters of GA.

Step2: Generate the initial population.

Step3: Modify the number of various micro sources to satisfy Formula (14).

Step4: Decode the chromosome and compute the individual fitness value and reliability index of the system.

Step5: Perform selecting, crossover and mutation operation.

Step6: See if the condition of iteration stopping is satisfied; if it is, finish the computation and output the results; if it is not, turn back to Step3.

Change the weight coefficient of the two objective functions constantly. Repeatedly compute the capacity configuration optimization scheme with different weight coefficients and the value of the two objective functions.

\section{ANALYSIS OF EXAMPLES}

\section{A. Introduction to example analysis system}

To verify the effectiveness of the model presented in this paper, capacity configuration optimization of microgrid is performed in an island region. The unit penalty fee for wind curtailment is $0.5 \$ / \mathrm{kWh}$. The peak load of system is $1 \mathrm{MW}$ and the load is recorded by hour.

Table 3 shows the parameters of different micro sources.

\begin{tabular}{|c|c|c|c|c|c|c|}
\hline $\begin{array}{c}\text { Micro } \\
\text { Source }\end{array}$ & $\begin{array}{c}\text { Per unit } \\
\text { minimum } \\
\text { capacity } \\
(\mathbf{k W})\end{array}$ & $\begin{array}{c}\text { Per unit } \\
\text { rated } \\
\text { capacity } \\
(\mathbf{k W})\end{array}$ & $\begin{array}{c}\text { Input } \\
\text { cost } \\
(\$ / \mathbf{k W})\end{array}$ & $\begin{array}{c}\text { Operating } \\
\text { maintenance } \\
\text { cost } \\
(\$ /(\mathbf{k W} \cdot \mathbf{a}))\end{array}$ & $\begin{array}{c}\text { Natural } \\
\text { gas cost } \\
\left(\$ / \mathbf{m}^{3}\right)\end{array}$ & $\begin{array}{c}\text { Service } \\
\text { life } \\
\text { (year) }\end{array}$ \\
\hline $\begin{array}{c}\text { Wind } \\
\text { turbine } \\
\text { generator }\end{array}$ & 0 & 45 & 1500 & - & - & 20 \\
\hline $\begin{array}{l}\text { Micro } \\
\text { turbine }\end{array}$ & 15 & 55 & 1000 & 120 & 0.5 & 20 \\
\hline Battery & - & $50(\mathrm{~kW} \cdot \mathrm{h})$ & 100 & - & - & - \\
\hline
\end{tabular}

TABLE III. PARAMETERS OF DIFFERENT MICRO SOURCES

Note: Battery life is related to its charge and discharge process. See the computation method in Section III.

\section{B. Optimal configuration scheme of isolated microgrid}

Using the proposed algorithm in section IV and the maximum loss of load probability allowed by the isolated microgrid is 0.001 . The relationship between the two objective functions, the total cost of input and operation and the penalty fee for wind curtailment, is extracted after repeated iterative computations, as shown in Fig .2.

As suggested by the figure, the penalty fee for wind curtailment shows a decline trend with the increase of the total cost of input and operation. This is mainly because fuel consumption costs a lot, and when the penalty fee for wind curtailment is low, fewer wind turbine generators are installed and the fuel consumption is high, which, as a result, raises the operating cost of the entire power grid; meanwhile, in order to reduce the penalty fee for wind curtailment, a considerable quantity of storage equipment should be installed to store surplus energies, which leads to the rise of input cost of the system.

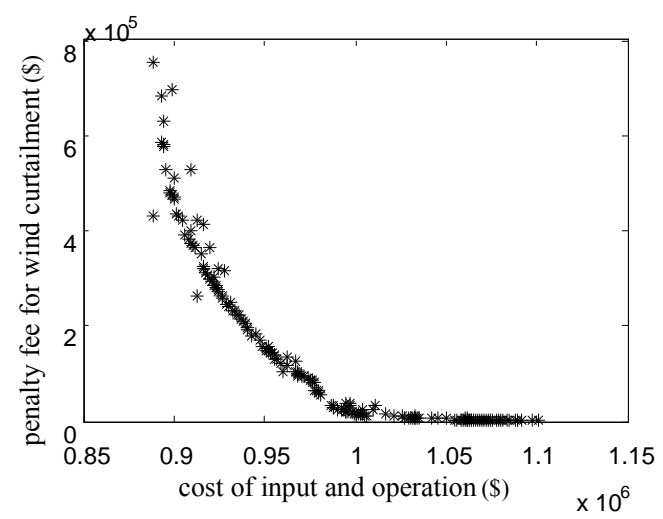

Figure 2. The relationship between the two objective functions

Based on the given wind speed and load data and with the set operating strategy, the capacity configuration optimization of isolated microgrid is discusses in two situations.

Situation 1: Assign 0.5 to both the weight coefficients of objective function $F_{1}$ and $F_{2}$, and convert them to single objective functions.

Situation 2: Take only objective function $F_{1}$ into account and consider only about power grid input cost, equipment replacement cost, operating maintenance cost, fuel consumption cost and environmental conversion fee. The penalty fee for wind curtailment is left out.

In these two situations, the optimal capacity configu- 
ration scheme is as shown in Table 4, and the cost in uniform annual value is as shown in Table 5.

TABLE IV.OPTIMAL CAPACITY CONFIGURATION SCHEME OF MICRO SOURCE

\begin{tabular}{cccc}
\hline Situation & $\begin{array}{c}\text { Number of wind } \\
\text { turbine generators }\end{array}$ & $\begin{array}{c}\text { Number of } \\
\text { micro tur- } \\
\text { bines }\end{array}$ & $\begin{array}{c}\text { Number of } \\
\text { batteries }\end{array}$ \\
\hline $\begin{array}{c}\text { Situation } \\
1\end{array}$ & 20 & 16 & 126 \\
$\begin{array}{c}\text { Situation } \\
2\end{array}$ & 36 & 16 & 84 \\
\hline
\end{tabular}

TABLE V.COST OF OPTIMAL CAPACITY CONFIGURATION SCHEME $10^{4} \$ / \mathrm{a}$

\begin{tabular}{ccccc}
\hline $\begin{array}{c}\text { Situa- } \\
\text { tion }\end{array}$ & $\begin{array}{c}\text { Input and } \\
\text { mainte- } \\
\text { nance cost }\end{array}$ & $\begin{array}{c}\text { Fuel con- } \\
\text { sumption } \\
\text { cost }\end{array}$ & $\begin{array}{c}\text { Environ- } \\
\text { mental con- } \\
\text { version fee }\end{array}$ & $\begin{array}{c}\text { Penalty } \\
\text { fee for } \\
\text { wind } \\
\text { curtail- } \\
\text { ment }\end{array}$ \\
\hline $\begin{array}{c}\text { Situa- } \\
\text { tion 1 }\end{array}$ & 43.915 & 51.431 & 0.321 & 3.882 \\
$\begin{array}{c}\text { Situa- } \\
\text { tion 2 }\end{array}$ & 63.085 & 25.527 & 0.159 & $(88.225)$ \\
\hline
\end{tabular}

Note: the content inside () in Table 5 is the computation result without considering the penalty fee for wind curtailment.

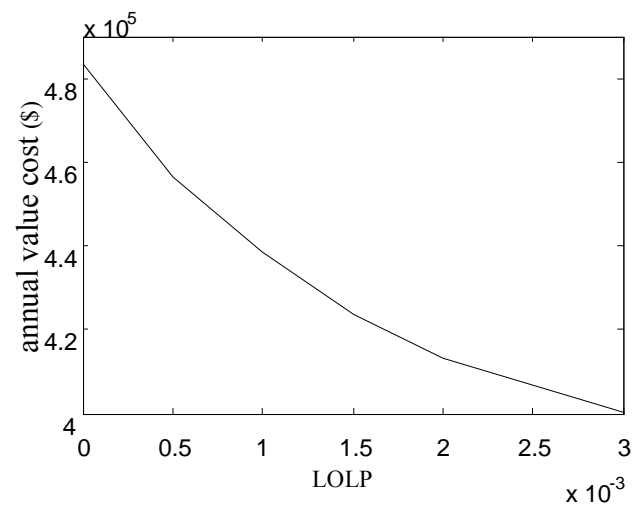

Figure 3. Relationship between annual value cost and LOLP

The comparison between the computation results of Situation 1 and 2 indicates that, when the penalty fee for wind curtailment is not considered, the per unit cost of wind turbine generator is high, therefore, the total input would rise. However, the power of the new energy is high, fuel consumption would be reduced and the total cost of fuel consumption would be reduced. In Situation 2, when the effect of penalty fee for wind curtailment is not considered, there are a large number of wind turbine generators but small capacity of storage equipment. In practical capacity configuration optimization of the microgrid, in order to reduce energy waste, the effect of the penalty fee for wind curtailment should be taken into account.

\section{Effect of reliability constraint on capacity configura- \\ tion optimization of the microgrid}

As shown in Fig .3. It is suggested that investment cost of the power grid increases as the system reliability rises and high reliability requirement can result in high investment cost. In the capacity configuration optimiza- tion of microgrid, rational reliability should be determined based on practical power grid needs.

\section{CONCLUSION}

On the basis of the current study, this paper analyzes the effect of the charge-discharge of lead-acid battery on its service life, develops the operating strategy of microgrid and builds an integrated comprehensive capacity configuration model of microgrid considering equipment input cost, operating maintenance cost, equipment replacement cost, fuel consumption cost, environmental conversion fee and penalty fee for wind curtailment.

Based on the statistical data of load and wind speed of an island region, capacity configuration optimization is conducted for an isolated microgrid with wind turbine generator, micro turbine and battery to verify the effectiveness and rationality of the proposed model. Moreover, the effect of penalty fee for wind curtailment and reliability constraint is analyzed. Results indicate that the effect of penalty fee for wind curtailment and reliability constraint should be appropriately considered in capacity configuration optimization of microgrid.

\section{REFERENCES}

[1] Lidula N W A,Rajapakse A D. "Microgrids research :A review of experimental microgrids and test systems". Renewable and Sustainable Energy Reviews,2011,15(1):186-202.

[2] Hatziargyriou N, Asano H, Iravani R, et al. "Microgrids". Power and Energy Magazine,2007,5(4): 78-94

[3] Huang Wei, Sun Changhui, Wu Ziping, et al. "Technical Research Overview of Microgrid with Distributed Generation System". Power System Technology, 2009.33(9):14-18

[4] Obara S,Watanabe S. "Optimization of equipment capacity and an operational method based on cost analysis of a fuel cell microgrid". International Journal of Hydrogen Energy,2012,37(9):7814-7830.

[5] Vallem M R,Mitra J. "Siting and sizing of distributed generation for optimal microgrid architecture". Proceeding of the 37th Annual North American Power Symposium,2005:611-616.

[6] Liubo, Zhang Yan, Yang Na. "Application of Improved Particle Swarm Optimization Algorithm in Locating and Constant Volume of Distributed Generator". Transactions of China Electrotechnical Society, 2008(2):203-107.

[7] Hong Yingyi,Lian Ruochen. "Optimal Sizing of Hybrid Wind/PV/Diesel Generation in a Stand-Alone Power System Using Markov-Based Genetic Algorithm". IEEE Transactions on Power Delivery,2012,27(2):640-647.

[8] Ding Ming, Wang Bo, Zhao Bo, et al. "Optimal Configuration of Capacity of Independent Wind/Solar/Diesel/Storage Microgrid System". Power System Technology, 2013, 37(3):575-581.

[9] Chen Jian, Wang Chengshan, Zhao Bo, et al. "Optimal Configuration of Independent Microgrid Considering Different Control Strategies". Automation of Electric Power Systems, 2013,37(11):1-6.

[10] Cui Mingyong. "Multi-objective Optimal Operation and Control Strategy Study of Microgrid”. Beijing: North China Electric Power University, 2011.

[11] Zhang Jietan, Cheng Haozhong, Hu Zechun, et al. "Probabilistic Production Simulation of Electrical Power System with Wind Power Plan". Proceedings of the CSEE, 2009,29(28):34-39.

[12] Qian Kejun, Yuan Yue, Shi Xiaodan, et al. "Environmental Benefit Analysis of Distributed Power Generation [J]. Proceedings of the CSEE, 2008,28(29):11-15.

Wang Xiaoping, Cao Liming. Genetic Algorithm: Theory, Application and Software Implementation". Xi'an: Xi'an Jiaotong University Press, 2002. 